\title{
PAC down-regulates estrogen receptor alpha and suppresses epithelial-to-mesenchymal transition in breast cancer cells
}

\author{
Huda A. Al-Howail ${ }^{1}$, Hana A. Hakami ${ }^{1,4,6}$, Basem Al-Otaibi ${ }^{2}$, Amer Al-Mazrou³, Maha H. Daghestani ${ }^{3}$,
} Ibrahim Al-Jammaz ${ }^{2}$, Huda H. Al-Khalaf ${ }^{1,5}$ and Abdelilah Aboussekhra ${ }^{1 *}$

\begin{abstract}
Background: Triple-negative breast cancer (TNBC) is an aggressive histological subtype with limited treatment options and very poor prognosis following progression after standard chemotherapeutic regimens. Therefore, novel molecules and therapeutic options are urgently needed for this category of patients. Recently, we have identified PAC as a curcumin analogue with potent anti-cancer features.

Methods: HPLC was used to evaluate the stability of PAC and curcumin in PBS and also in circulating blood. Cytotoxicity/apoptosis was assessed in different breast cancer cell lines using propidium iodide/annexinV associated with flow cytometry. Furthermore, immunoblotting analysis determined the effects of PAC on different oncogenic proteins and pathways. Additionally, the real time xCELLigence RTCA technology was applied to investigate the effect of PAC on the cellular proliferation, migration and invasion capacities.

Results: PAC is more stable than curcumin in PBS and in circulating blood. Furthermore, we have shown differential sensitivity of estrogen receptor-alfa positive $\left(\mathrm{ERa}^{+}\right)$and estrogen receptor alfa negative $\left(\mathrm{ERa}^{-}\right)$breast cancer cells to PAC, which down-regulated ERa in both cell types. This led to complete disappearance of ERa in $\mathrm{ERa}^{-}$cells, which express very low level of this receptor. Interestingly, specific down-regulation of ERa in receptor positive cells increased the apoptotic response of these cells to PAC, confirming that ERa inhibits PAC-dependent induction of apoptosis, which could be mediated through ERa down-regulation. Additionally, PAC inhibited the proliferation and suppressed the epithelial-to-mesenchymal transition process in breast cancer cells, with higher efficiency on the TNBC subtype. This effect was also observed in vivo on tumor xenografts. Additionally, PAC suppressed the expression/secretion of 2 important cytokines IL-6 and MCP-1, and consequently inhibited the paracrine procarcinogenic effects of breast cancer cells on breast stromal fibroblasts.
\end{abstract}

Conclusion: These results indicate that PAC could be considered as important candidate for future therapeutic options against the devastating TNBC subtype.

Keywords: PAC, ERa, Breast cancer, EMT

\footnotetext{
* Correspondence: aboussekhra@kfshrc.edu.sa

${ }^{1}$ Department of Molecular Oncology, King Faisal Specialist Hospital and

Research Center, MBC \# 03, PO BOX 3354, Riyadh 11211, Kingdom of Saudi

Arabia

Full list of author information is available at the end of the article
} 


\section{Background}

Despite advances in diagnosis and treatment, breast cancer remains a major public health problem and a major cause of death for women worldwide $[1,2]$. Recent gene expression profiling studies have shown that this heterogeneous disease is composed of five major biological subtypes: luminal A, luminal B, HER2-enriched, basal-like, and normal breast-like [3]. The majority of basal-like breast cancers exhibit a triple-negative phenotype (ER $\alpha^{-}$, progesterone receptor-negative ( $\left.\mathrm{PR}^{-}\right)$, Her2-neu-negative) and high frequency of p53 mutations [4]. Triple negative breast cancer is an aggressive histological subtype with poor prognosis and high rates of relapse following chemotherapy as compared to other subtypes $[4,5]$. Nevertheless, studies of neoadjuvent chemotherapy suggest that women with TNBC who have a pathological complete response to treatment achieve excellent outcome (Carey LA 2007, Liedtke C 2008). Unfortunately, disease recurrence is very frequent, and conventional treatments for relapsed patients are limited. Therefore, there is an urgent unmet need for the development of novel generation of drugs with high efficiency and specificity against this particular group of patients.

$E R \alpha$ is a ligand-activated transcription factor, which plays major roles in breast carcinogenesis. Indeed, ER $\alpha$ signaling pathway is one of the most important pathways in hormone-dependent breast cancer. The amplification of the ER $\alpha$ coding gene ESR1 is frequent in various breast tumors as well as in benign and precancerous breast diseases, suggesting that ESR1 amplification may be a common mechanism in proliferative breast disease and a very early genetic alteration in a large subset of breast cancers [6]. Thereby, it's reasonable to consider $E R \alpha$ inhibitors of significant clinical interest.

Several dietary phytochemicals have shown promising anti-cancer properties, and have been used as therapeutic agents against various illnesses for centuries [7]. Curcumin (diferuloylmethane), the major active component of the spice turmeric, has been widely used in traditional medicines for thousands of years [8]. Several in vitro and in vivo studies as well as clinical trials have shown that curcumin has potent anti-cancer effects, and safe even at high doses. However, curcumin exhibits poor aqueous solubility and low absorption in the gastrointestinal tract, which limits its clinical use [9]. To bypass this limitation, several curcumin analogues were synthesized, with the hope to increase the efficacy while preserving the same safety profile. PAC (4-hydroxy-3methoxybenzylidene)-N-methyl-4-piperidone) is a promising anti-cancer curcumin analogue. Indeed, PAC is 5 times more efficient than curcumin in inducing apoptosis in breast cancer cells [10]. In the present study we have shown that PAC is more stable than curcumin in PBS and in circulating blood. Furthermore, PAC-dependent cytotoxicity is more potent on $\mathrm{ER}^{-}$cells than $\mathrm{ER}^{+}$cells through down-regulation of ER $\alpha$. Moreover, PAC inhibits the pro-metastatic epithelial-to-mesenchymal transition (EMT) process in breast cancer cells, with higher efficiency on the TNBC subtype. Additionally, PAC suppressed the paracrine procarcinogenic effects of breast cancer cells on breast stromal fibroblasts via suppressing the secretion of two important cytokines IL-6 and MCP-1.

\section{Methods}

\section{Ethics statement}

Animal experiments were approved by the King Faisal Specialist Hospital and Research Center institutional Animal Care and Use Committee (ACUC) under the RAC proposal \# 2080009, and were conducted according to relevant national and international guidelines. Animals suffered only needle injection pain and also certain degree of pain/ distress related to the growth/ burden of the tumor. The euthanasia was performed using cervical dislocation.

\section{Cells and cell culture}

The human breast cancer cell lines were all obtained from the American Type Culture Collection (ATCC). Cells were cultured following the instructions of the company. NBF-1 are primary normal breast fibroblasts developed from tissues obtained from plastic surgery, and cultured as previously described [11]. All supplements were obtained from Sigma (Saint Louis, MO, USA) except for antibiotic and antimycotic solutions, which were obtained from Gibco (Grand Island, NY, USA).

\section{Cellular lysate preparation and immunoblotting}

This has been performed as previously described [12]. Antibodies directed against Vimentin (RV202), Twist1, $\mathrm{N}$-cadherin and interleukin-6 (IL-6) were purchased from Abcam (Cambridge, MA); Akt, phospho-Akt (193H12), Erk1/2, phospho-Erk1/2 (THR202/TYR204), E-cadherin (24E10) and MCP-1 from Cell Signaling (Danvers, MA); c-Myc from BD Biosciences (San Jose, CA); Cyclin D1 (HD11), ER $\alpha$ (F-10) and glyceraldehydes3-phosphate dehydrogenase (GAPDH, FL-335), were purchased from Santa Cruz (Santa Cruz, CA).

\section{RNA purification and quantitative RT-PCR}

Total RNA was purified using the TRI reagent (Sigma) according to the manufacturer's instructions, and was treated with RNase-free DNase before cDNA synthesis using the Advantage RT Kit (Clontech). For quantitative RT-PCR, the RT $^{2}$ Real-Time ${ }^{\text {Tm }}$ SYBR Green qPCR mastermix (Qiagen, UK) was used and the amplifications were performed utilizing the Bio-Rad iQ5 multicolor Real time PCR detection system. The melting-curve data were collected to check PCR specificity, and the amount of PCR products was measured by threshold cycle $(\mathrm{Ct})$ 
values and the relative ratio of specific genes to GAPDH for each sample was then calculated. The respective primers are:

GAPDH: 5'-GAGTCCACTGGCGTCTTC-3' and 5'GGGGTGCTAAGCAGTTGGT-3'; CCND1: 5' -TGTTCGTGGCCTCTAAGATGAAG-3' and 5'- AGGTTCCACTTGAGCTTGTTCAC-3' c-MYC: 5' - CTTCTCTCCGTCCTCGGATTCT-3' and 5'-GAAGGTGATCCAGACTCTGACCTT-3'

\section{Transfection}

The pGFP-C-shLenti plasmid bearing ESR1-shRNA or scrambled shRNA (Origene), were used at $1 \mu \mathrm{g} / \mathrm{ml}$ each for transfection of 293FT cells. Lentiviral supernatants were collected $48 \mathrm{~h}$ post-transfection. Culture media were removed from the target cells and replaced with the lentiviral supernatant and incubated for $24 \mathrm{~h}$ in the presence of $1 \mu \mathrm{g} / \mathrm{ml}$ polybrene (Sigma-Aldrich). Transduced cells were selected after $48 \mathrm{~h}$ with puromycin (Invitrogen).

\section{Bioavailability of PAC and curcumin}

For the bioavailability experiments, normal Balb/c mice ( $n=3 \times 5,25 \mathrm{~g}, 3$ mice/time point) were intraperitoneally injected with PAC or curcumin $(100 \mathrm{mg} / \mathrm{Kg}) .400 \mu \mathrm{L}$ blood samples were withdrawn directly from the heart of each mouse into a heparin-rinsed vial at 15, 30, 45, 60 and 120 min post-injection. Each blood sample was centrifuged at $3000 \times g$ for $5 \mathrm{~min}$. The resulting plasma sample $(100 \mu \mathrm{L})$ was acidified using hydrochloric acid $(\mathrm{HCl}$ $6 \mathrm{~N}, 10 \mu \mathrm{L}$ ) followed by three times extraction with a mixture of ethyl acetate:propanol (9:1, $1 \mathrm{~mL})$. The extract was then completely dried and re-dissolved in methanol $(100 \mu \mathrm{L})$ before direct injection onto HPLC for analysis. Using a standard curve of PAC and curcumin, the data obtained from analyzed samples were utilized to construct pharmacokinetic curve of PAC/curcumin concentrations in plasma using the Graph Pad Prism software. Separate experiments using the same extraction system were carried out to determine extraction efficiency of PAC and curcumin from plasma and showed a yield of $96 \%$.

\section{HPLC analyses}

Reversed-phase HPLC were performed on Jasco, HPLC systems using $C_{18}$ column $(10 \mu \mathrm{m}, 4.6 \times 250 \mathrm{~mm})$ (Econosil, Alltech, USA). HPLC was run using a gradient of $0.1 \%$ TFA in water (solvent A) and $0.1 \%$ TFA in $\mathrm{CH}_{3} \mathrm{CN}$ (solvent B) gradient, 0 to $50 \% \mathrm{~B}, 15 \mathrm{~min}, 50$ to $50 \% \mathrm{~B}, 5 \mathrm{~min}, 50$ to $0 \% \mathrm{~B}, 5 \mathrm{~min}$, and 100 to $100 \% \mathrm{~A}$, $5 \mathrm{~min}$ each at flow rate of $1 \mathrm{~mL} / \mathrm{min}$. The HPLC systems are equipped with a UV detector set at $420 \mathrm{~nm}$, a Flowcount $\gamma$-radioactivity detection system (Bioscan, USA) and Lauralite analysis program (LabLogic, UK).

\section{Cell migration, invasion and proliferation}

These assays were performed as described in detail previously [13]. Cell migration, invasion and proliferation were assessed in a real-time, non-invasive, and label-free manner using the xCELLigence RTCA technology (Roche). Migration and invasion were assessed as per the manufacturer's instructions using the CIM-plate 16. Briefly, initially $160 \mu \mathrm{l}$ of cell-free complete media, or SFM were added to the lower chamber wells and $30 \mu \mathrm{l}$ of SFM to the upper chamber wells and plates were incubated for $1 \mathrm{~h}$ in the cell incubator to obtain equilibrium. Subsequently, the background signal was measured and exponentially growing cells resuspended in $100 \mu \mathrm{l}$ of SFM were seeded in the upper chamber wells with a thin layer of matrigel basement membrane (invasion) or without (migration). Cells were seeded at $1-3 \times 10^{4}$ cells/well. After cell addition CIM-plates 16 were incubated for $30 \mathrm{~min}$ at room temperature in the laminar flow. Subsequently, the plates were locked in the RTCA DP device in the incubator. Each condition was performed in triplicate.

For proliferation assays, exponentially growing cells in complete media $\left(0.5-1 \times 10^{4} /\right.$ well $)$ were seeded in Eplates as per manufacturer's instructions. The rest of the procedure was the same as for the invasion and migration assays. Relative cell migration, invasion and proliferation levels are shown in arbitrary units.

\section{Apoptosis analysis by annexin V/flow cytometry}

Cells were either not treated or challenged with PAC or curcumin, and then harvested, centrifuged and stained with propidium iodide (PI) and Alexa Flour 488 annexin V (Molecular Probes, Eugene, OR, USA) as previously described [14].

\section{Protein arrays}

SFCM were applied to RayBio the human cytokine array 5 (AAH-CYT-5, RayBiotech, Inc (Norcross, GA, USA) as per manufacturer's instructions. Signal densities were assessed with the ImageJ software, and data analysis was carried out following the Array protocol's instructions.

\section{Tumor xenografts}

Breast cancer xenografts were created in nude mice by subcutaneous injection of MDA-MB-231 cells, and then the animals were treated with PAC $(100 \mathrm{mg} / \mathrm{Kg})$ or DMSO as previously described [10].

\section{Statistical analysis}

Student's $t$-test was used for statistical analysis and $p$ values $\leq 0.05$ were considered as statistically significant.

\section{Conditioned media}

Cells were cultured in medium without serum for $24 \mathrm{~h}$, and then media were collected and briefly centrifuged, 
and cells were counted. The resulting supernatants (SFCM) were used either immediately or were frozen at $-80{ }^{\circ} \mathrm{C}$ until needed. SFCM were diluted, when necessary, based on the cell counts.

\section{Results}

PAC is more stable than curcumin in PBS and circulating blood

To compare the stability of curcumin with that of PAC, we have first studied the stability of both molecules in phosphate buffer $(0.1 \mathrm{M}, \mathrm{pH} 7.4)$. PAC and curcumin were incubated in PBS for different periods of time $(0,5$, $30 \mathrm{~min}$ ), and then were analyzed by HPLC. Both PAC and curcumin were instable in PBS at $37^{\circ} \mathrm{C}$, but PAC showed higher stability (Fig. 1a). Indeed, after $30 \mathrm{~min}$ of incubation more than $90 \%$ of curcumin was decomposed, while only $60 \%$ of PAC was decomposed (Fig. 1b). This indicates that after 30 min of incubation PAC was 4 times more stable than curcumin in PBS.

In order to test the bioavailability of curcumin and PAC in animals, normal Balb/c mice $(n=30)$ were intraperitonealy injected with PAC or curcumin $(100 \mathrm{mg} / \mathrm{Kg})$. $400 \mu \mathrm{L}$ blood samples were withdrawn directly from the heart of each mouse at 15, 30, 45, 60 and 120 min postinjection. The resulting plasma extracts were completely dried and re-dissolved in methanol $(100 \mu \mathrm{L})$ before injection onto HPLC for analysis. Figure 1c shows that the amount of PAC presents in plasma at $15 \mathrm{~min}$ postinjection reached $35 \mu \mathrm{g} / \mathrm{mL}$, while the level of curcumin was only $10.3 \mu \mathrm{g} / \mathrm{mL}$. The level of PAC further increased in blood reaching its maximum level $(40 \mu \mathrm{g} / \mathrm{mL}) 45 \mathrm{~min}$ post-injection, and dropped to $10 \mu \mathrm{g} / \mathrm{mL}$ at $60 \mathrm{~min}$ postinjection, then remained relatively constant during the following $60 \mathrm{~min}$ (Fig. 1c). On the other hand, the level of curcumin decreased in a time-dependent manner reaching a level as low as $0.3 \mu \mathrm{g} / \mathrm{mL} 120$ min postinjection. This shows that $25 \%$ of the injected PAC was still in blood $2 \mathrm{~h}$ post-injection, and that PAC is 30 times more stable than curcumin in circulating blood.

\section{PAC induces apoptosis in breast cancer cells with higher efficiency on basal-like cells}

To measure the extent and the nature of cell death induced by PAC on various breast cancer cell lines, the fluorochrome-conjugated annexin V/PI stain test was used and cells were analyzed by a flow cytometer. Different cell lines were used including basal-like, ER $\alpha^{-}$(MDA-MB-231, MDA-MB-468, BT-20, and BT-549), luminal, ER $\alpha^{+}$(MCF7, T-47D and BT-474), and HER2-enriched, ER $\alpha^{-}$(SK-BR3). Sub-confluent cells were treated either with DMSO (used as control) or with PAC $(10 \mu \mathrm{M})$ for $72 \mathrm{~h}$. Figure $2 \mathrm{a}$ shows the presence of four different cell populations after the double staining annexin V/PI and sorting by flow cytometry: live cells (normal) (annexin V-/PI-), early apoptotic cells (Apo) (annexin V+/PI-), late apoptotic cells (Late apo) (annexin $\mathrm{V}+/ \mathrm{PI}+$ ) and necrotic cells (Necrotic) (annexin V-/PI+). Importantly, PAC induced cell death mainly by apoptosis in all breast cancer cells (Fig. 2a).

Figure $2 \mathrm{~b}$ presents cell death of different cell lines after treatment with PAC as percentages relative to DMSO-

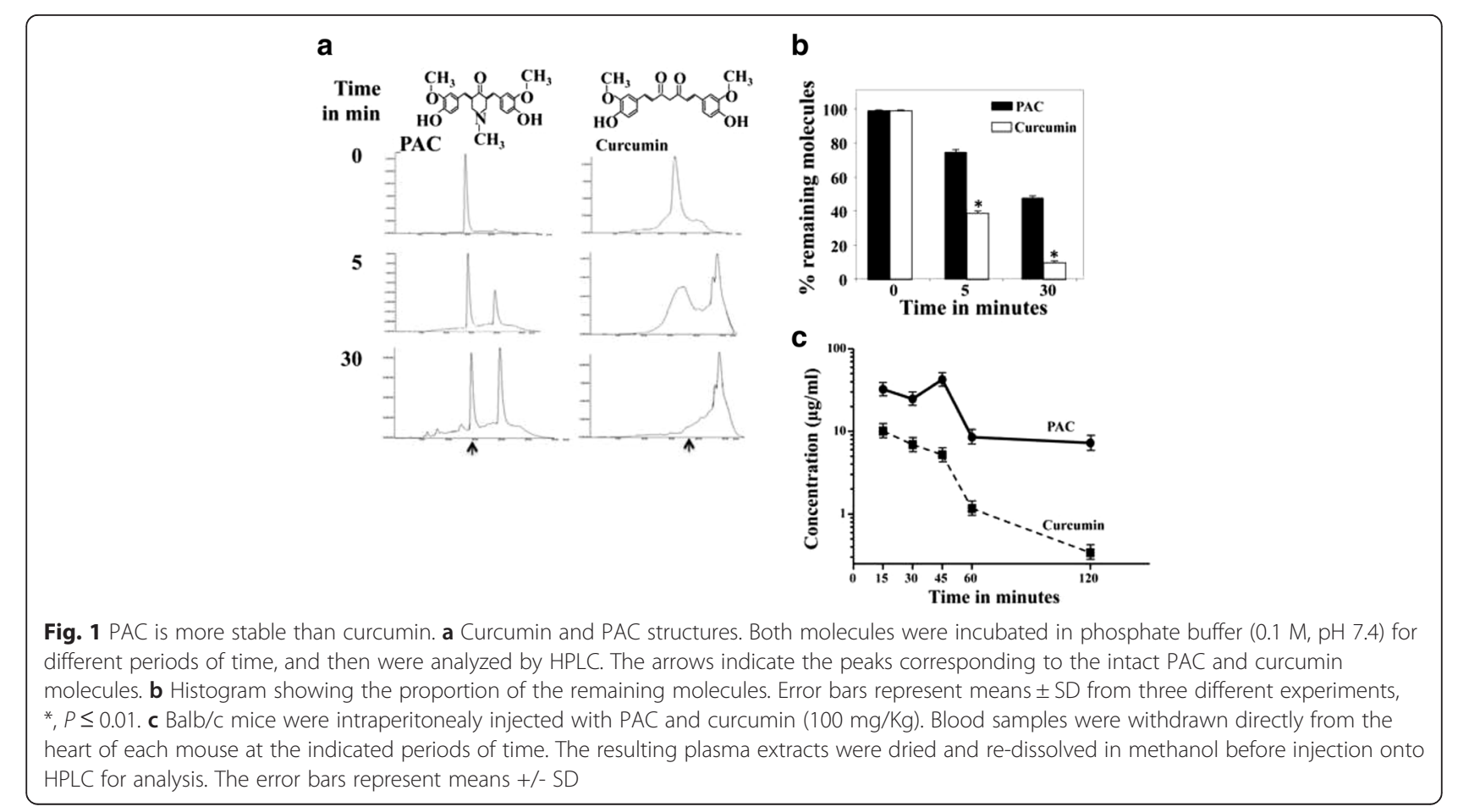




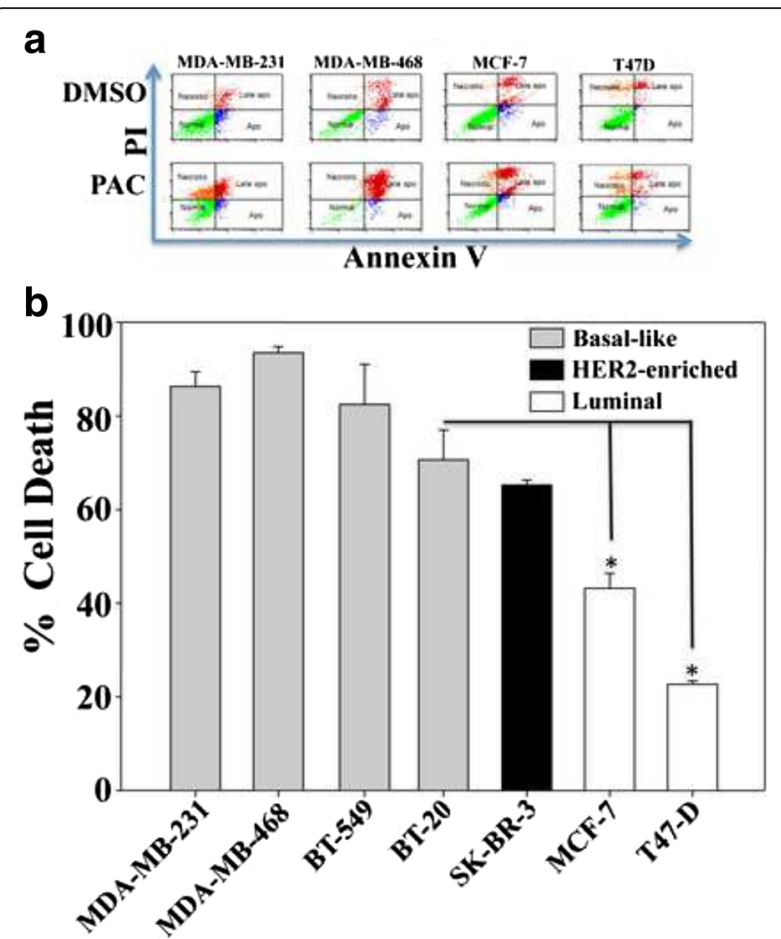

Fig. 2 PAC triggers apoptosis more efficiently in ERa-negative than in ERa-positive breast cancer cells. Cells were either sham-treated or challenged with PAC $(10 \mu \mathrm{M})$ for $72 \mathrm{~h}$, and then cell death was assessed by annexin V/PI in association with flow cytometry. a Charts. b Histogram showing the proportion of cell death (apoptosis + necrosis) in each cell line. Error bars represent means \pm SD from three different experiments, ${ }^{*}, P \leq 0.05$

treated cells. The real effect of PAC was obtained by discarding the proportion of dead cells obtained in the control samples from the treated ones for each cell line. In addition, the proportion of total cell death was considered as the sum of necrosis and both early and late apoptosis. 80-90\% of basal-like cells (MDA-MB-231, MDA-MB-468, BT-20, and BT-549) and about $65 \%$ of HER2-enriched cells (SK-BR-3) underwent cell death in response to PAC (Fig. 2b). While in luminal cells, only $45 \%$ of MCF-7 cells and $25 \%$ of T-47D cells died upon PAC treatment (Fig. 2b). This indicates that PAC is cytotoxic against various types of breast cancer cells, and its effect is more potent on the ER $\alpha^{-}$subtype.

\section{Specific ERa down-regulation sensitizes breast cancer cells to PAC}

To explore the role of ER $\alpha$ in PAC-dependent induction of apoptosis, we knocked-down the ESR1 gene in MCF7 cells using specific ESR1-shRNA, and a scrambled sequence was used as control. Figure 3a shows strong ER $\alpha$ down-regulation by the ESR1-shRNA1, while ESR1shRNA2 and ESR1-shRNA3 had only marginal effects. Similar effect was observed on the ER $\alpha$ target c-Myc
(Fig. 3a). Subsequently, these cells were either shamtreated (DMSO) or challenged with PAC $(10 \mu \mathrm{M})$ for 3 days, and then cell death was assessed by AnnexinV/PI as described above. Figure $3 \mathrm{~b}$ and $\mathrm{c}$ shows that while PAC triggered apoptosis in only about $35 \%$ of cells bearing control-shRNA, ESR1-shRNA2 or ESR1-shRNA3, the proportion of apoptotic cells reached $70 \%$ in MCF-7 cells expressing ESR1-shRNA1. This shows that ER $\alpha$ down-regulation plays a major role in PAC-induced apoptosis in breast cancer cells.

\section{PAC down-regulates ERa, c-Myc and cyclin D1}

We then set out to test the effect of PAC on the expression of ER $\alpha$ in both types of cells (ER $\alpha$-positive and negative). To this end, MDA-MB-231 and MCF-7 cells were exposed to PAC $(10 \mu \mathrm{M})$ and were harvested after different periods of time $(0,8,24,48,72 \mathrm{~h})$. Cell lysates were prepared and $100 \mu \mathrm{g} / \mathrm{ml}$ of proteins were used for immunoblotting analysis using specific anti- ER $\alpha$ antibody, and GAPDH was utilized as internal control. The level of ER $\alpha$ decreased in both cell lines, but became undetectable after $24 \mathrm{~h}$ of treatment in MDA-MB-231 cells, while a significant amount of the protein was still present in MCF-7 cells even after $72 \mathrm{~h}$ of treatment (Fig. 4a). The ER $\alpha$ protein is a well-known positive regulator of cyclin D1 and c-Myc, two important apoptosis modulators in breast cancer cells [15]. Therefore, we investigated the effect of PAC on the expression of these two proteins. Figure 4a shows that the levels of both proteins started to decrease after $24 \mathrm{~h}$ of treatment and continue to decline in a time-dependent manner in MDA-MB-231. On the other hand, the effect of PAC on cyclin D1 and c-Myc was only marginal in MCF-7 cells (Fig. 4a). To confirm this finding, we tested the effect of PAC on CCND1 and $c-M Y C$ mRNAs. MDA-MB-231 and MCF-7 cells were either sham-treated (DMSO) or challenged with PAC $(10 \mu \mathrm{M})$ for $24 \mathrm{~h}$ and total RNA was purified and used for amplification by quantitative RT-PCR using specific primers. Figure $4 \mathrm{~b}$ shows that while PAC strongly down-regulated both genes in MDAMB-231 cells, it increased the level of $c-M Y C$ and had only marginal effect on cyclin D1 in MCF-7 cells. This confirms the strong effect of PAC on ER $\alpha$ in ER $\alpha^{-}$breast cancer cells and indicates that this gene as well as its targets $c-M Y C$ and $C C N D 1$ might play important roles in the response of these cells to PAC. To further validate these findings we tested the effect of PAC on these three genes in tumor xenografts formed subcutaneously in nude mice upon injection of MDA-MB-231 [10]. The immunoblotting shows PAC-dependent down-regulation of the 3 genes in xenogratft tissues isolated from PACtreated animals as compared to control animals treated with DMSO (Fig. 4c). 


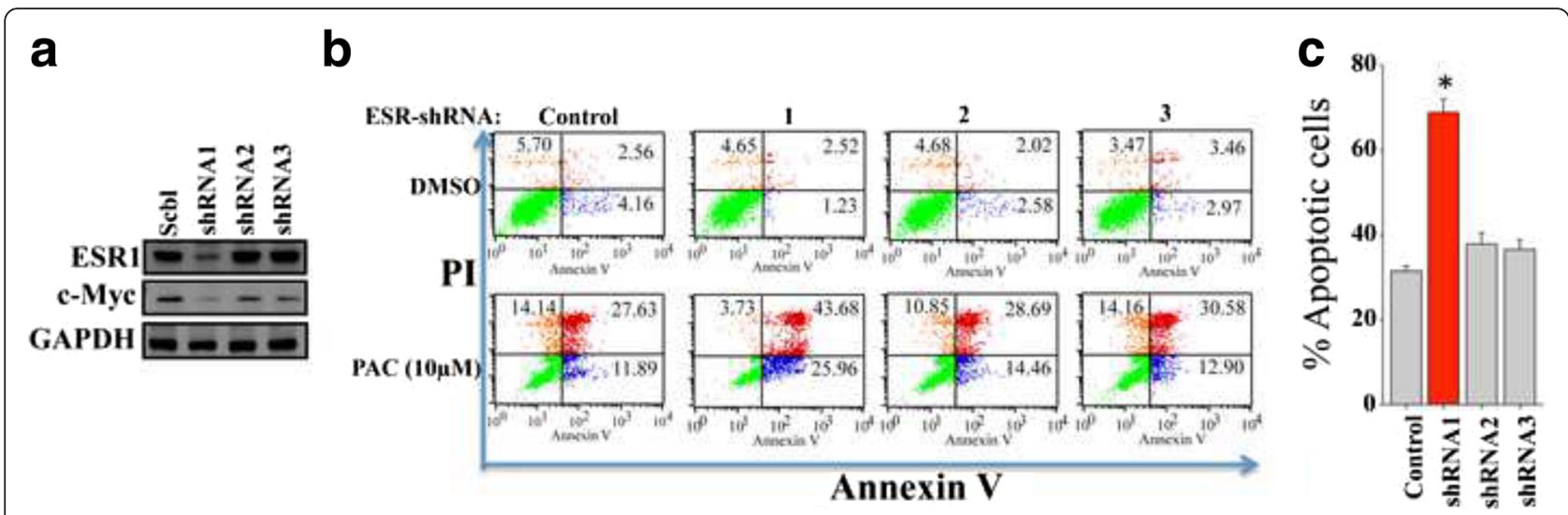

Fig. 3 ERa down-regulation potentiates the pro-apoptotic effect of PAC. MCF-7 cells were transfected with vectors containing 3 different ESR1-shRNA sequences $(1,2,3)$ or a scrambled sequence $(\mathrm{Scbl})$. a Cell lysates were prepared and used for immunoblotting analysis using antibodies against the indicated proteins. $\mathbf{b}$ Cells were treated with PAC $(10 \mu \mathrm{M})$ and the proportion of apoptotic cells was determined using annexinV/PI-Flow cytometry. $\mathbf{c}$ Histogram, Error bars represent means \pm S.D from three different experiments, ${ }^{*}, P \leq 0.005$

PAC suppresses the epithelial-to-mesenchymal transition process both in vitro and in vivo

Since estrogen receptor signaling plays a role in the prometastatic epithelial-to-mesenchymal transition (EMT) process, we sought to investigate the effect of PAC on EMT in both $\mathrm{ER}^{+}$and $\mathrm{ER}^{-}$cells. To this end, MDA-MB231 and MCF-7 cells were either sham-treated or challenged with PAC $(10 \mu \mathrm{M})$, and then cell proliferation was assessed using the xCELLigence RTCA technology utilizing the Eplates. Figure 5a shows strong PAC-dependent inhibition of cell proliferation of both MDA-MB-231 and MCF-7 cells, with a more pronounced effect on the $\mathrm{ER}^{-}$cells.

Next, we investigated the effect of PAC on the migration/ invasion abilities using the xCELLigence RTCA technology utilizing CIM-plate 16. Figure 5b shows that PAC inhibits the migration and the invasion capabilities of both cell lines, with an effect more pronounced on the ER $\alpha^{-}$MDAMB-231 cells as compared to the ER $\alpha^{+}$MCF-7 cells.

To elucidate the molecular basis of this decrease in the migration/invasion abilities, we tested the effect of PAC on the pro-invasive/migratory protein kinases ERK1/2 and AKT. Therefore, MDA-MB-231 and MCF-7 cells were either sham-treated or challenged with PAC $(10 \mu \mathrm{M})$ for $24 \mathrm{~h}$, and then cell lysates were prepared and total levels as well as the phosphorylated/active forms of these two proteins were assessed by immunoblotting. Figure 5c shows strong PAC-dependent inhibition of both protein kinases AKT and ERK1/2 in both

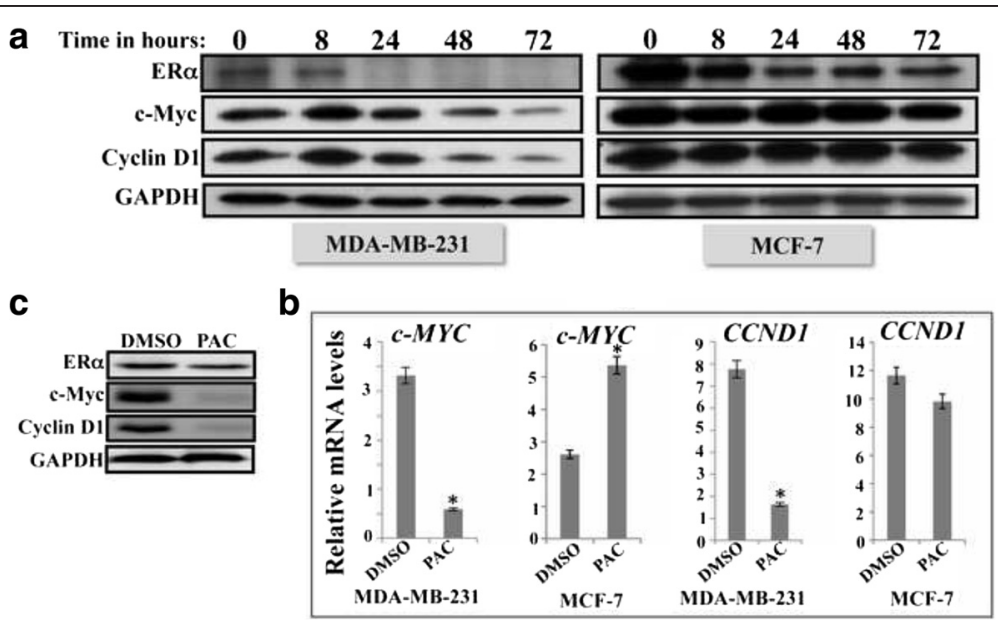

Fig. 4 PAC down-regulates ERa and its targets C-Myc and cyclin D1. a Cells were challenged with PAC (10 $\mu M)$ for the indicated periods of time, and then cell lysates were prepared and used for immunoblotting analysis utilizing specific antibodies against the indicated proteins. $\mathbf{b}$ Cells were either sham-treated (DMSO) or challenged with PAC (10 $\mu \mathrm{M})$ for $24 \mathrm{~h}$, and then total RNA was extracted and used for qRT-PCR using specific primers for the indicated genes. Error bars represent means \pm S.D from three different experiments, ${ }^{*}, P \leq 0.05$. c Nude mice bearing sub-cutaneous humanized tumor xenografts were treated with DMSO or PAC, and then cell lysates were prepared from excised tumors and used form immunoblotting utilizing specific antibodies against the indicated proteins 


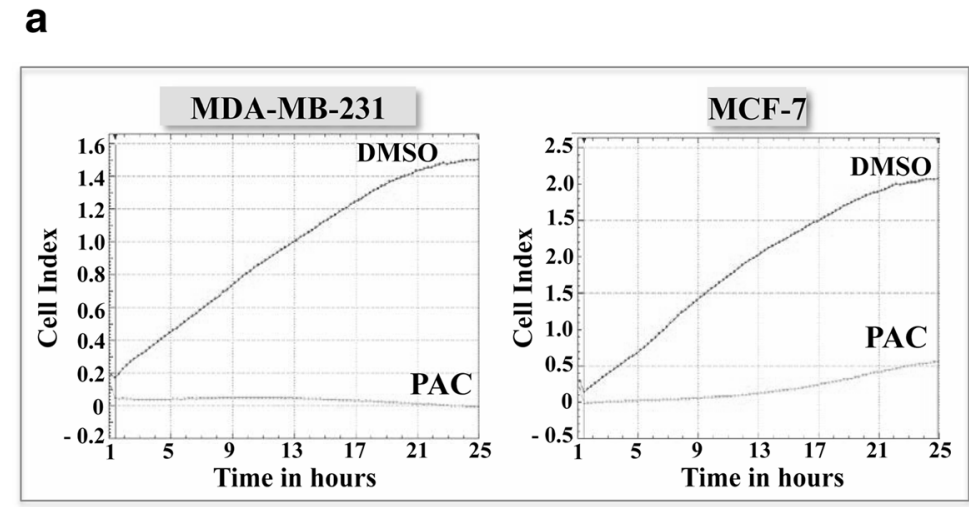

b

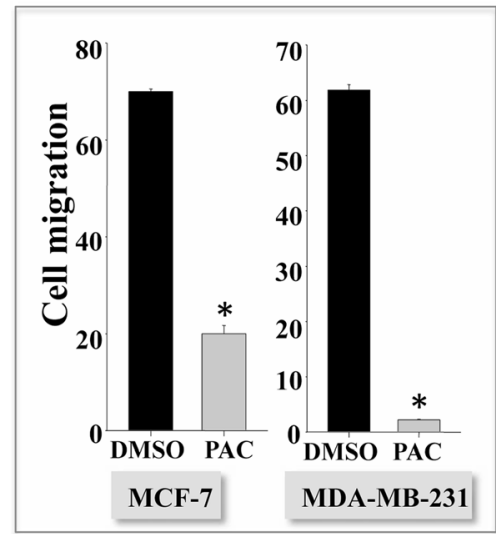

\section{c}

C

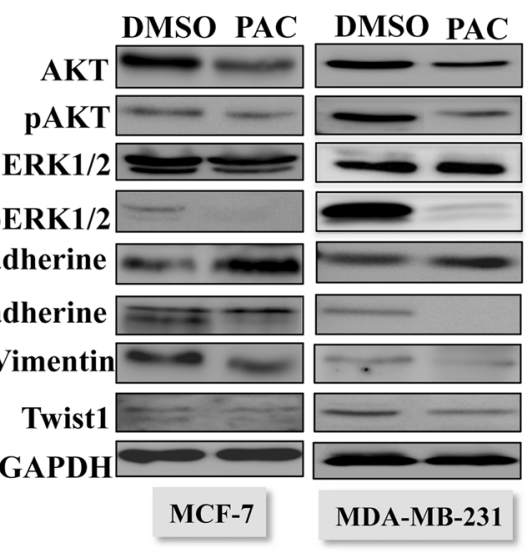

d

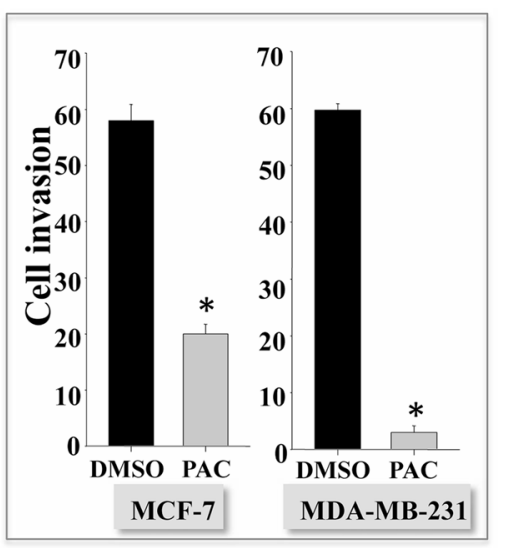

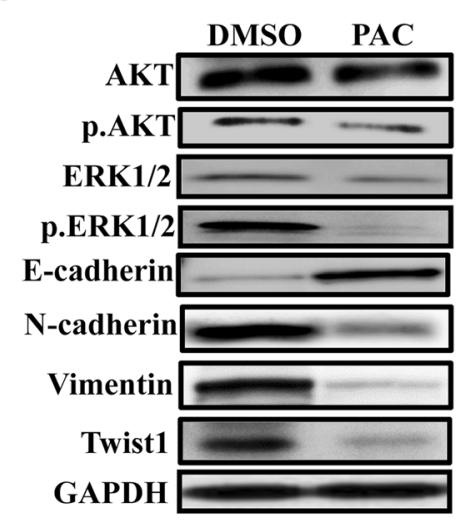

Fig. 5 PAC suppresses EMT in breast cancer cells and tumor xenografts. a Cells were seeded in E-16 plates for $24 \mathrm{~h}$, and then were either sham-treated (DMSO) or exposed to PAC $(10 \mu \mathrm{M})$ for the indicated periods of time. Cell proliferation was monitored in real time using the RTCA-DP xCELLigence System. b Cells were exposed to DMSO or PAC $(10 \mu \mathrm{M})$ for $24 \mathrm{~h}$, and then were seeded in the CIM-plate with SFM in the upper wells separated by 8 micron pore size PET membrane with thin layer of matrigel basement membrane matrix (invasion) or without (migration). The lower chambers contained complete media as chemoattractant. Cells were incubated in normal culture conditions for $24 \mathrm{~h}$ and the migration/invasion were determined using the real time RTCA-DP xCELLigence System. Error bars represent means \pm S.D from 3 different experiments; ${ }^{*}, P \leq 0.001$. c Cells were either sham-treated (DMSO) or challenged with PAC $(10 \mu \mathrm{M})$ for $24 \mathrm{~h}$, and then cell lysates were prepared and used for Immunoblotting analysis using antibodies against the indicated proteins. d Figure legends as in Fig. 4c

cell lines, with a higher effect on MDA-MB-231 cells. Indeed, the inhibition of ERK1/2 was very strong in the TNBC cells (Fig. 5b). Since the activation of these two protein kinases is part of EMT, we investigated the possible PAC-dependent inhibition of this pro-metastatic process, through testing the effect on the expression of specific mesenchymal and epithelial markers by immunoblotting. Figure 5c shows clear PAC-dependent up-regulation of E-cadherin in MCF-7 cells, while the levels of all tested mesenchymal markers ( $\mathrm{N}$-cadherin, vimentin and Twist-1) were reduced in both cell lines, but the effect was more pronounced in MDA-MB-231 cells as compared to MCF-7 cells. Interestingly, similar results were obtained in vivo on tumor xenografts upon sub-cutaneous injection of MDA-MB231 cells in nude mice followed by intraperitoneal treatment with PAC (100 mg/Kg) (Fig. 5d). Indeed, PAC inhibited the two important protein kinases AKT and ERK1/2 and also upregulated E-cadherin, while it down-regulated the mesenchymal markers N-cadherin, vimentin and twist1 (Fig. 5d). Together, these results indicate that PAC suppresses the EMT process in breast cancer cells both ER $\alpha$-positive and -negative, with a more potent effect on ER $\alpha^{-}$cells.

\section{PAC inhibits the expression/secretion of the pro-} metastatic MCP-1 and IL- 6 cytokines

Human cytokine antibody arrays were used to detect the differentially expressed cytokines in the conditioned media obtained from MDA-MB-231 cells either shamtreated (DMSO) or challenged with PAC $(10 \mu \mathrm{M})$. This experiment showed the differential expression of several cykokines, including IL-6, MCP-1, IL-5 and angiogenin (Fig. 6a and b). The effect on IL-6 and MCP-1 is of great importance since these two cytokines play important 


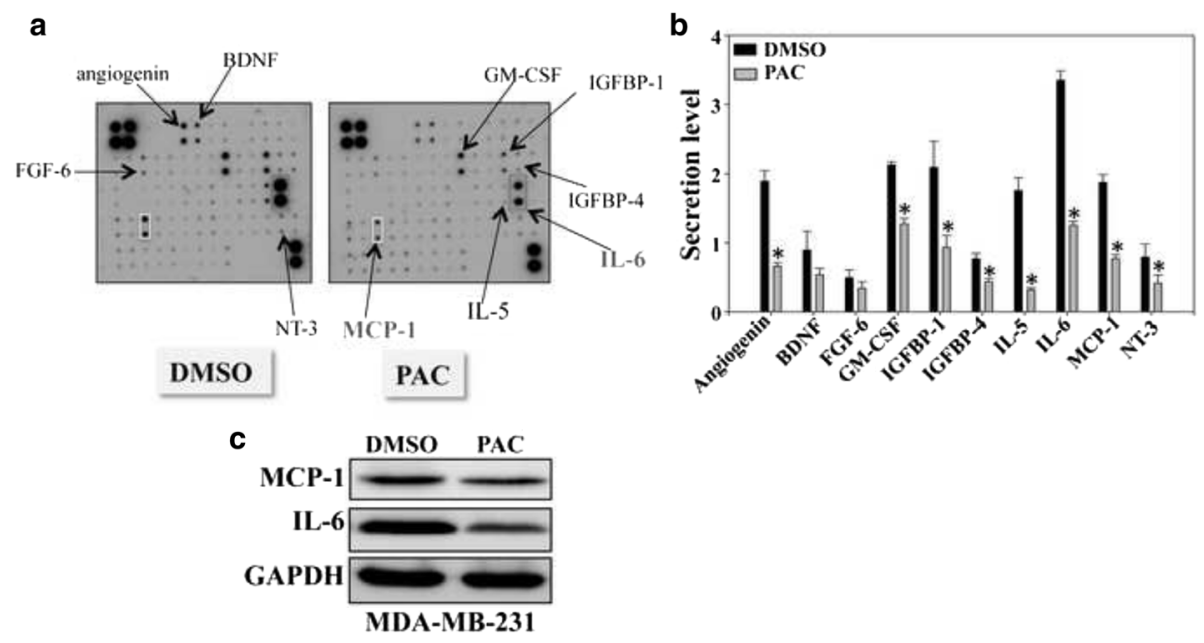

Fig. 6 PAC inhibits the expression/secretion of IL-6 and MCP-1. SFCM from MDA-MB-231 cells either sham treated (DMSO) or challenged with PAC $(10 \mu \mathrm{M})$ for $24 \mathrm{~h}$ were collected and applied onto Human Cytokine Antibody Array membrane. a Blots, the rectangles indicate the spots corresponding to IL- 6 and MCP-1, while the arrows indicate differentially expressed cytokines. $\mathbf{b}$ Histogram showing secretion levels of the indicated cytokines upon quantification. Error bars represent means \pm S.D, ${ }^{*}, P \leq 0.05$. c Cells were exposed to DMSO or PAC, and then cell lysates were prepared and used for immunoblotting analysis using specific antibodies against the indicated proteins

roles in the spread of various types of cancer, including breast carcinomas [16]. Therefore, we tested the effect of PAC on the expression of these two cytokines at the protein level. The immunoblotting analysis shows strong PAC-dependent down-regulation of both IL-6 and MCP-1 in MDA-MB-231 cells (Fig. 6c).

\section{PAC suppresses the paracrine effects of breast cancer cells on breast stromal fibroblasts}

After showing PAC-dependent inhibition of IL-6/MCP-1 expression and secretion from breast cancer cells we sought to test the effect of PAC on the paracrine effects of these cells on breast stromal fibroblasts. To this end, MDA-MB-231 cells were first either sham-treated (DMSO) or challenged with PAC $(10 \mu \mathrm{M})$ for $24 \mathrm{~h}$. Subsequently, cells were cultured in serum-free medium (SFM) for $24 \mathrm{~h}$, and then serum-free conditioned media (SFCM) were collected and utilized to challenge normal breast stromal fibroblast cells NBF-1 for $24 \mathrm{~h}$. Proliferation, migration and invasion of stromal fibroblasts were assessed with the xCELLigence RTCA technology. Figure 7a shows PACdependent inhibition of the paracrine effects of MDA-MB231 cells on the proliferation rate of fibroblast cells. Similarly, media conditioned with PAC-treated MDA-MB231 cells strongly suppressed the migration/invasion abilities of breast stromal fibroblasts (Fig. 7b). Together, these results indicate that PAC inhibits the pro-metastatic effects of the highly invasive breast cancer cells MDA-MB-231.

\section{Discussion}

Triple-negative breast cancers are poorly differentiated, highly malignant and have a poor outcome. Duration of response is usually short, with rapid relapse very common and median survival of advanced disease of just 13 months, which is much less than the median duration of survival observed in other advanced subtypes $[17,18]$. This made TNBC one of the most attractive areas of research in oncology $[19,20]$.

We have shown here that the newly synthesized curcumin analogue PAC is 4 times more stable than curcumin in PBS and 30 times more stable than curcumin in circulating blood in mice (Fig. 1). This higher bioavailability of PAC is of great importance since the low bioavailability of curcumin limits its potential use in the clinic. Additionally, we present strong evidence that PAC is a potent antibreast cancer agent with the strongest effects on the TNBC subtype cells. Indeed, PAC exhibited higher cytotoxicity against different TNBC cells (MDA-MB-231, MDA-MB468, BT-20 and BT-549) than luminal cells (MCF-7 and T47D). Likewise, PAC inhibited the proliferation of breast cancer cells with higher effect on $\mathrm{ER}^{-}$cells than on $\mathrm{ER}^{+}$ cells. Interestingly, when ER $\alpha$ was down-regulated in MCF-7 cells with specific shRNA, the pro-apoptotic effect of PAC was doubled. This clearly showed that high expression of ER $\alpha$ limited PAC cytotoxic effects on breast cancer cells, and we hypothesized that PAC-dependent apoptosis could be mediated through ER $\alpha$ down-regulation. Therefore, we tested the effect of PAC on the expression of ER $\alpha$ in cells that express high and low level of this receptor, and have shown that PAC reduced ER $\alpha$ level in both types of cells, but in the ER $\alpha^{-}$cells ER $\alpha$ became undetectable, while its level was still high in $\mathrm{ER \alpha}^{+}$cells despite its diminution. This provided a meaningful explanation to the higher effect of PAC on ER $\alpha^{-}$cells, and corroborated the result obtained 

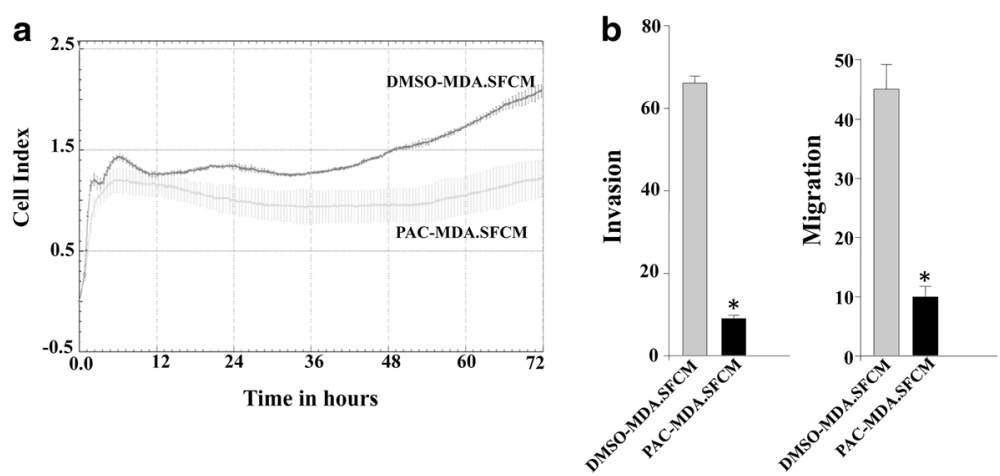

Fig. 7 PAC suppresses the paracrine procarcinogenic effects of breast cancer cells. SFCM from MDA-MB-231 cells either exposed to DMSO (DMSO-MDA-SFCM) or challenged with PAC $(10 \mu \mathrm{M})$ (PAC-MDA-SFCM) was used for indirect co-culturing of NBF-1 fibroblasts cells for $24 \mathrm{~h}$, and then cell proliferation (a) as well as migration/invasion (b) were assessed using the real time RTCA-DP xCELLigence System as described in Fig. 4. Error bars represent means \pm S.D from three different experiments; ${ }^{*}, P \leq 0.001$

by specific down-regulation of ER $\alpha$ in cells that express this receptor. This also confirmed our previous results showing that expression of the receptor coding gene ESR1 in $E R \alpha^{-}$breast cancer cells increased their resistance to PAC [10]. Together, these results indicate that PAC-related induction of apoptosis in breast cancer cells depends on the cellular level of ER $\alpha$. In fact, various laboratory studies demonstrated that reduced estrogen levels induced apoptosis [21]. A cyclopentenone derivative (CTC-35) was also shown to have potent proapoptotic activity in $\mathrm{ER}^{-}$breast cancer cells [22]. Furthermore, green tea EGCG decreased the proliferation rates of breast cancer cells through strong down-regulation of ER $\alpha$ [23].

PAC-dependent down-regulation of ER $\alpha$ in MDA-MB231 cells was accompanied with a strong decrease in the level of ER $\alpha$ main targets c-Myc and cyclin D1, both in vitro and in vivo. However, c-Myc and cyclin D1 were not down-regulated in MCF-7 cells, and the c-MYC mRNA was rather up-regulated after $24 \mathrm{~h}$ of PAC treatment (Fig. 4b). This difference in the c-MYC mRNA and protein levels upon PAC treatment could result from translational of post-translational regulatory process in MCF-7 cells. cMYC and cyclin D1 are two major oncogenes, which confer proliferative and anti-apoptosis capacities to breast cancer cells [15], and are associated with altered sensitivity to endocrine therapy [24]. The c-Myc protein plays a major role in the apoptotic response of breast cancer cells [25]. This protein has been found overexpressed in $45 \%$ breast tumors [26]. Cyclin D1 is an oncogene that is overexpressed in about $50 \%$ of all breast cancer cases [27], and its down-regulation is an important target in breast cancer therapy [28]. Therefore, PAC-related targeting of these two oncogenes could be of great therapeutic value.

In addition, we have shown that PAC suppresses the EMT process in both $\mathrm{ER}^{+}$and $\mathrm{ER} \alpha^{-}$cell lines, with a higher effect on ER $\alpha$-negative cells (Fig. 5). EMT is currently considered as pivotal event in the initial step of the metastatic cascade that allows cells to acquire migratory, invasive and stem-like properties [29]. Evolving evidence indicates that ER $\alpha$ signaling can directly regulate EMT-related transcriptional factors, indicating that ER $\alpha$ might be a key regulator of the EMT program [30-33]. PAC inhibited the migration/invasion abilities of breast cancer cells through inhibiting the ERK1/2 and AKT protein kinases, and repressed the mesenchymal markers vimentin and $\mathrm{N}$ cadherin. Similar effects were also observed in vivo on tumor xenografts, wherein PAC increased the expression of E-cadherin and repressed N-cadherin, vimentin, AKT and Twist1. Similarly, it has been previously shown that curcumin plays an important role in the inhibition of lipopolysaccharide-induced EMT in breast cancer cells through the down-regulation of NF-kB-Snail activity [34].

In addition to their high migratory and invasiveness capacities, $\mathrm{ER} \alpha^{-}$cells secrete high amounts of prometastatic cytokines such as IL- 6 and MCP-1, which can activate stromal cells including fibroblasts [16, 35, 36]. Interestingly, $\mathrm{PAC}$ reduced the secreted levels of several cytokines including IL- 6 and MCP-1 from MDA-MB231 cells. This repressed the paracrine pro-replicative and -invasive/migratory effects of these highly invasive cells on breast stromal fibroblasts. This shows the ability of PAC in inhibiting the pro-metastatic capabilities of MDA-MB-231 cells. Indeed, there exists abundant evidence demonstrating that active stromal fibroblasts play major roles in breast cancer progression and spread [37]. These cells escort cancer cells through the whole carcinogenesis process. Therefore, targeting active stromal fibroblasts or blocking their cross-talk with cancer cells is a promising therapeutic approach $[38,39]$.

\section{Conclusions}

We have shown here that PAC has better bioavailability than curcumin. Moreover, we present clear evidence that PAC down-regulates ER $\alpha$ and triggers apoptosis in breast 
cancer cells with higher efficiency on receptor negative cells. Furthermore, PAC suppressed the prometastatic features of the invasive breast cancer cells by suppressing EMT and the paracrine effect on breast stromal fibroblasts. This makes PAC as a valuable candidate for the future armada against the devastating TNBC type of tumors.

\section{Abbreviations}

ATCC, American type culture collection; DMSO, dimethyl sulfoxide; EMT, epithelial-to-mesenchymal transition; ERa, estrogen receptor alfa; GAPDH, glyceraldehyde-3-phosphate dehydrogenase; PBS, phosphate buffered saline; RT-PCR, reverse transcriptase-polymerase chain reaction; shRNA, short hairpin RNA

\section{Acknowledgements}

We thank the Research Center Administration for their continuous support. This work was performed under the RAC proposal \# 2080009.

\section{Funding}

This study was not funded.

\section{Availability of data and materials}

The datasets supporting the conclusions of this article are included within the article.

\section{Authors' contributions}

HAA, HAH, BA, AAI, HHA carried out the experiments. MHD and IA conceived the project. AA conceived the project, supervised research and wrote the manuscript. All authors read and approved the final manuscript.

\section{Competing interests}

The authors declare that they have no competing interests.

\section{Consent for publication}

Not applicable.

\section{Ethics approval and consent to participate}

Animal experiments were approved by the King Faisal Specialist Hospital and Research Center institutional Animal Care and Use Committee (ACUC) under the RAC proposal \# 2080009.

\section{Author details}

'Department of Molecular Oncology, King Faisal Specialist Hospital and Research Center, MBC \# 03, PO BOX 3354, Riyadh 11211, Kingdom of Saudi Arabia. ${ }^{2}$ Department of Cyclotron and Radiopharmaceuticals, King Faisal Specialist Hospital and Research Center, Riyadh 11211, Kingdom of Saudi Arabia. ${ }^{3}$ Stem Cell Therapy Program, King Faisal Specialist Hospital and Research Center, Riyadh 11211, Kingdom of Saudi Arabia. ${ }^{4}$ Department of Zoology, College of Science, King Saud University, Riyadh 11451, Kingdom of Saudi Arabia. ${ }^{5}$ The National Center for Genomics Research, King Abdulaziz City for Science and Technology, Riyadh 11211, Kingdom of Saudi Arabia.

${ }^{6}$ Present Address: McGill University Health Center, Montreal, QC, Canada.

Received: 12 January 2016 Accepted: 19 July 2016

Published online: 27 July 2016

\section{References}

1. Formenti SC, Arslan AA, Love SM. Global breast cancer: the lessons to bring home. Int J breast cancer. 2012;2012:249501.

2. Siegel R, Naishadham D, Jemal A. Cancer statistics, 2012. CA Cancer J Clin. 2012:62(1):10-29.

3. Perou CM, Sorlie T, Eisen MB, van de Rijn M, Jeffrey SS, Rees CA, Pollack JR, Ross DT, Johnsen H, Akslen LA, et al. Molecular portraits of human breast tumours. Nature. 2000;406(6797):747-52.

4. Metzger-Filho O, Tutt A, de Azambuja E, Saini KS, Viale G, Loi S, Bradbury I, Bliss JM, Azim Jr HA, Ellis $P$, et al. Dissecting the heterogeneity of triplenegative breast cancer. J Clin Oncol. 2012;30(15):1879-87.

5. Carey L, Winer E, Viale G, Cameron D, Gianni L. Triple-negative breast cancer: disease entity or title of convenience? Nat Rev Clin Oncol. 2010; 7(12):683-92.
6. Holst F, Stahl PR, Ruiz C, Hellwinkel O, Jehan Z, Wendland M, Lebeau A, Terracciano L, Al-Kuraya K, Janicke F, et al. Estrogen receptor alpha (ESR1) gene amplification is frequent in breast cancer. Nat Genet. 2007;39(5):655-60.

7. Garg AK, Buchholz TA, Aggarwal BB. Chemosensitization and radiosensitization of tumors by plant polyphenols. Antioxid Redox Signal. 2005;7(11-12):1630-47.

8. Wang H, Khor TO, Shu L, Su ZY, Fuentes F, Lee JH, Kong AN. Plants vs. cancer: a review on natural phytochemicals in preventing and treating cancers and their druggability. Anticancer Agents Med Chem. 2012;12(10): $1281-305$.

9. Prasad S, Tyagi AK, Aggarwal BB. Recent developments in delivery, bioavailability, absorption and metabolism of curcumin: the golden pigment from golden spice. Cancer Res Treat. 2014:46(1):2-18.

10. Al-Hujaily EM, Mohamed AG, Al-Sharif I, Youssef KM, Manogaran PS, AlOtaibi B, Al-Haza'a A, Al-Jammaz I, Al-Hussein K, Aboussekhra A. PAC, a novel curcumin analogue, has anti-breast cancer properties with higher efficiency on ER-negative cells. Breast Cancer Res Treat. 2011;128(1):97-107.

11. Hawsawi NM, Ghebeh H, Hendrayani SF, Tulbah A, Al-Eid M, Al-Tweigeri T, Ajarim D, Alaiya A, Dermime S, Aboussekhra A. Breast carcinoma-associated fibroblasts and their counterparts display neoplastic-specific changes. Cancer Res. 2008:68(8):2717-25.

12. Al-Mohanna MA, Al-Khalaf HH, Al-Yousef N, Aboussekhra A. The p16INK4a tumor suppressor controls p21WAF1 induction in response to ultraviolet light. Nucleic Acids Res. 2007;35(1):223-33.

13. Silva $G$, Aboussekhra A. p16 inhibits the pro-metastatic potentials of osteosarcoma cells through targeting the ERK pathway and TGF-beta1. Mol Carcinog. 2015;55(5):525-36.

14. Al-Khalaf HH, Colak D, Al-Saif M, Al-Bakheet A, Hendrayani SF, Al-Yousef N Kaya N, Khabar KS, Aboussekhra A. p16(INK4a) positively regulates cyclin D1 and E2F1 through negative control of AUF1. PLoS One. 2011:6(7):e21111.

15. Xu J, Chen Y, Olopade OI. MYC and breast cancer. Genes Cancer. 2010;1(6): $629-40$.

16. Rokavec M, Wu W, Luo JL. IL6-mediated suppression of miR-200C directs constitutive activation of inflammatory signaling circuit driving transformation and tumorigenesis. Mol Cell. 2012;45(6):777-89.

17. Dent R, Trudeau M, Pritchard KI, Hanna WM, Kahn HK, Sawka CA, Lickley LA Rawlinson E, Sun P, Narod SA. Triple-negative breast cancer: clinical features and patterns of recurrence. Clin Cancer Res. 2007:13(15 Pt 1):4429-34.

18. Foulkes WD, Smith IE, Reis-Filho JS. Triple-negative breast cancer. N Engl J Med. 2010;363(20):1938-48.

19. Bosch A, Eroles P, Zaragoza R, Vina JR, Lluch A. Triple-negative breast cancer: molecular features, pathogenesis, treatment and current lines of research. Cancer Treat Rev. 2010:36(3):206-15.

20. Turner NC, Reis-Filho JS. Tackling the diversity of triple-negative breast cancer. Clin Cancer Res. 2013:19(23):6380-8.

21. Lewis-Wambi JS, Jordan VC. Estrogen regulation of apoptosis: how can one hormone stimulate and inhibit? Breast Cancer Res. 2009:11(3):206.

22. Ciucci A, Gianferretti P, Piva R, Guyot T, Snape TJ, Roberts SM, Santoro MG Induction of apoptosis in estrogen receptor-negative breast cancer cells by natural and synthetic cyclopentenones: role of the IkappaB kinase/nuclear factor-kappaB pathway. Mol Pharmacol. 2006;70(5):1812-21.

23. De Amicis F, Russo A, Avena P, Santoro M, Vivacqua A, Bonofiglio D, Mauro L, Aquila S, Tramontano D, Fuqua SA, et al. In vitro mechanism for downregulation of ER-alpha expression by epigallocatechin gallate in ER+/PR+ human breast cancer cells. Mol Nutr Food Res. 2013:57(5):840-53.

24. Butt AJ, McNeil CM, Musgrove EA, Sutherland RL. Downstream targets of growth factor and oestrogen signalling and endocrine resistance: the potential roles of c-Myc, cyclin D1 and cyclin E. Endocr Relat Cancer. 2005; 12 Suppl 1:S47-59.

25. Kang Y, Cortina R, Perry RR. Role of c-myc in tamoxifen-induced apoptosis estrogen-independent breast cancer cells. J Natl Cancer Inst. 1996;88(5):279-84.

26. Naidu R, Wahab NA, Yadav M, Kutty MK. Protein expression and molecular analysis of c-myc gene in primary breast carcinomas using immunohistochemistry and differential polymerase chain reaction. Int J Mol Med. 2002;9(2):189-96

27. Bartkova J, Lukas J, Strauss M, Bartek J. Cyclin D1 oncoprotein aberrantly accumulates in malignancies of diverse histogenesis. Oncogene. 1995;10(4): 775-8.

28. Yang C, Trent S, Ionescu-Tiba V, Lan L, Shioda T, Sgroi D, Schmidt EV. Identification of cyclin D1- and estrogen-regulated genes contributing to breast carcinogenesis and progression. Cancer Res. 2006;66(24):11649-58. 
29. Cowin P, Welch DR. Breast cancer progression: controversies and consensus in the molecular mechanisms of metastasis and EMT. J Mammary Gland Biol Neoplasia. 2007;12(2-3):99-102.

30. Ye Y, Xiao Y, Wang W, Yearsley K, Gao JX, Barsky SH. ERalpha suppresses slug expression directly by transcriptional repression. Biochem J. 2008; 416(2):179-87.

31. Ye Y, Xiao Y, Wang W, Yearsley K, Gao JX, Shetuni B, Barsky SH. ERalpha signaling through slug regulates E-cadherin and EMT. Oncogene. 2010; 29(10):1451-62.

32. Al Saleh S, Al Mulla F, Luqmani YA. Estrogen receptor silencing induces epithelial to mesenchymal transition in human breast cancer cells. PLoS One. 2011;6(6):e20610.

33. Bouris P, Skandalis SS, Piperigkou Z, Afratis N, Karamanou K, Aletras AJ, Moustakas A, Theocharis AD, Karamanos NK. Estrogen receptor alpha mediates epithelial to mesenchymal transition, expression of specific matrix effectors and functional properties of breast cancer cells. Matrix Biol. 2015;43:42-60.

34. Huang T, Chen Z, Fang L. Curcumin inhibits LPS-induced EMT through downregulation of NF-kappaB-Snail signaling in breast cancer cells. Oncol Rep. 2013;29(1):117-24.

35. Hendrayani SF, Al-Khalaf HH, Aboussekhra A. The cytokine IL-6 reactivates breast stromal fibroblasts through transcription factor STAT3-dependent Up-regulation of the RNA-binding protein AUF1. J Biol Chem. 2014;289(45): 30962-76

36. Tsuyada A, Chow A, Wu J, Somlo G, Chu P, Loera S, Luu T, Li AX, Wu X, Ye W, et al. CCL2 mediates cross-talk between cancer cells and stromal fibroblasts that regulates breast cancer stem cells. Cancer Res. 2012;72(11):2768-79.

37. Tu G, Liu Z, Liu M, Luo H. Cancer-associated fibroblasts: a multifaceted driver of breast cancer progression. Cancer Lett. 2015;361(2):155-63.

38. Togo S, Polanska UM, Horimoto Y, Orimo A. Carcinoma-associated fibroblasts are a promising therapeutic target. Cancers. 2013;5(1):149-69.

39. Dittmer J, Leyh B. The impact of tumor stroma on drug response in breast cancer. Semin Cancer Biol. 2015;31C:3-15.

\section{Submit your next manuscript to BioMed Central and we will help you at every step:}

- We accept pre-submission inquiries

- Our selector tool helps you to find the most relevant journal

- We provide round the clock customer support

- Convenient online submission

- Thorough peer review

- Inclusion in PubMed and all major indexing services

- Maximum visibility for your research

Submit your manuscript at www.biomedcentral.com/submit 